\title{
Aqueous Solutions of Polyethoxylated Fatty Alcohols Rheological behavior and superficial properties
}

\begin{abstract}
ANDRA TAMAS, SABINA NITU*
Politehnica University Timisoara, Faculty of Industrial Chemistry and Environmental Engineering, 6 V. Parvan Blvd., 300223, Timisoara, Romania

The paper presents the study of the rheological and superficial behavior (foaming power and wetting capacity) of some aqueous solutions with polyethoxylated fatty alcohols content. The influence of fatty alcohols concentration and their degree of ethoxylation as well as that of temperature on the rheological behavior was determined from the dependences between the shear stress $\tau$ and the shear rate $\dot{\gamma}$. The results demonstrate that all the studied solutions have non-Newtonian behavior, with flow behavior index smaller than 1.
\end{abstract}

Keywords: apparent viscosity, non-Newtonian behavior, polyethoxylated alcohols

Polyethoxylated fatty alcohols are probably the most important group of nonionic surfactants due their rapid biodegradability and low toxicity of metabolites. They have hydroxyl or ether bond which will not ionize in water [1].

Polyethoxylated alcohols are based on synthetic or natural fatty alcohols and have the general formula $\mathrm{R}^{-} \mathrm{CH}_{2}-$ $\mathrm{O}-\left(\mathrm{CH}_{2}-\mathrm{CH}_{2}-\mathrm{O}\right)-\mathrm{H}$, where $\mathrm{R}$ represents the alkyl group of the parent alcohol and $\mathrm{n}$ is the number of the ethoxyl units. Natural polyethoxylated fatty alcohols generally contain $\mathrm{C}_{6}-\mathrm{C}_{2}$ linear chains. The degree of ethoxylation as well as the chain length, branching and saturation decide on the surface activity and other physical properties of ethoxylated alcohols [2,3].

$C_{1618}$ fatty alcohol (cetostearyl) ethoxylates is used as detergents in heavy-duty washing pow ders, as dispersing agents and solubilizers, as wetting agents for industrial applications in aqueous solutions, as emulsifiers for $\mathrm{O} / \mathrm{W}$ emulsions of oils, fats, paraffin, polyolefin waxes and silicone oil emulsions and as emulsifiers for emulsion polymerization [4-6]. Ethoxylated products influence the stability of emulsions by altering the solubility and flow characteristics [7].

The aim of this work was to analyse the rheological behavior of aqueous solutions with various concentrations of polyethoxylated fatty alcohols. It was followed the influence of surfactant concentration and degree of ethoxylation, as well as that of temperature, on the rheological behavior. In addition, rheological relations $\tau=\mathrm{f}(\dot{\gamma})$ were established, and it was calculated the activation energy of viscous flow.

\section{Experimental part}

For the preparation of aqueous solutions of nonionic surfactants, fatty alcohol $C_{16 / 18}$ ethoxylated with 50 (AGE_50) and 20 (AGE_20) moles of ethylene oxide respéctively, was used. The main physicochemical properties of these products are given in table 1.

The samples preparation was done at $50^{\circ} \mathrm{C}$, by dispersing the nonionic surfactant in water with a mechanical stirrer with diameter $45 \mathrm{~mm}$, which provides an intense stirring $\left(R e=5 \times 10^{4}\right)$ corresponding to a peripheral velocity of 3.5 $\mathrm{m} \mathrm{s}^{-1}$. The composition of the samples is presented in table 2.

The rheological measurements were carried out under thermostatic conditions, at different temperatures ranging from 25 to $50^{\circ} \mathrm{C}$, using a Rheotest-2 rotation viscometer with the system vat-drum $S / S$, suitable for the viscosity range of these fluids and higher sensibility. The device allows the measurement of the torsion moment appeared thanks to the ring-shaped substance layer placed between a fixed cylinder and a rotating one with known revolution. The torsion moment is correlated with the shear stress. The revolution and the ring-shaped layer thickness determine the shear rate. Shear rate values were changed in the range $81 \div 1312 \mathrm{~s}^{-1}$. The samples were analysed after one day of preparation.

Table 1

THE PROPERTIES OF ETHOXYLATED FATTY ALCOHOLS $[8,9]$

\begin{tabular}{|l|c|c|}
\hline \multirow{2}{*}{ Property } & \multicolumn{2}{|c|}{ Conditions of admissibility/Value } \\
\cline { 2 - 3 } & AGE_50 & AGE_20 \\
\hline Average molecular weight, g mol ${ }^{-1}$ & 2456 & 1136 \\
\hline Appearance at $25^{\circ} \mathrm{C}$ & White waxy solid (flakes) \\
\hline Physical state changement, ${ }^{\circ} \mathrm{C}$ & $52-56$ & $40-45$ \\
\hline Cloud point $(1 \%$ in $10 \% \mathrm{NaC1}),{ }^{\circ} \mathrm{C}$ & $74-78$ & $75-77$ \\
\hline pH of aq. sol. $5 \%$ & \multicolumn{2}{|c|}{$5-7$} \\
\hline Ethylene Oxide content, $\%$ w/w & 89.57 & 77.46 \\
\hline HLB & 17.8 & 15.4 \\
\hline Hydroxyl number, $\mathrm{mg} \mathrm{KOH} \mathrm{g}{ }^{-1}$ & $21-27$ & $47-55$ \\
\hline Kinematic viscosity, cSt & $102\left(70^{\circ} \mathrm{C}\right)$ & $82\left(50^{\circ} \mathrm{C}\right)$ \\
\hline
\end{tabular}

*email: sabina.nitu@upt.ro; Phone: 0256404231 


\begin{tabular}{|c|c|c|c|c|c|}
\hline \multirow{2}{*}{ Sample } & \multicolumn{2}{|c|}{ Composition, wt. \% } & \multirow{2}{*}{ Sample } & \multicolumn{2}{c|}{ Composition, wt.\% } \\
\cline { 2 - 3 } \cline { 6 - 6 } & AGE_50 & Water & & AGE_20 & Water \\
\hline A1 & 5 & 95 & B1 & 5 & 95 \\
\hline A2 & 10 & 90 & B2 & 10 & 90 \\
\hline A3 & 12.5 & 87.5 & B3 & 12.5 & 87.5 \\
\hline A4 & 15 & 85 & B4 & 15 & 85 \\
\hline A5 & 17.5 & 82.5 & B5 & 17.5 & 82.5 \\
\hline A6 & 20 & 80 & B6 & 20 & 80 \\
\hline
\end{tabular}

Table 2

THE COMPOSITION OF THE SAMPLES

\section{Results and discussions}

The influence of temperature on the rheological behavior was determined for all the samples. In figure 1, dependence $\tau=f(\dot{\gamma})$ is shown, at three temperature values, for solution A3(12.5 wt.\% AGE 50) and B3 (12.5 wt.\% AGE 20).

The obtained rheological equations are shown in table 3 and suggest that these solutions have a pseudoplastic behavior, which corresponds to the Ostwald de Waele rheological model [10-13]:

$$
\tau=K \cdot \dot{\gamma}^{n}
$$

where $\mathrm{K}$ is the consistence coefficient and $n$ is the flow index.

Both the graphical representation and the values of the flow index show that, at the same temperature, the samples containing AGE 50 exhibit higher shear stress values than those with AGE_20.

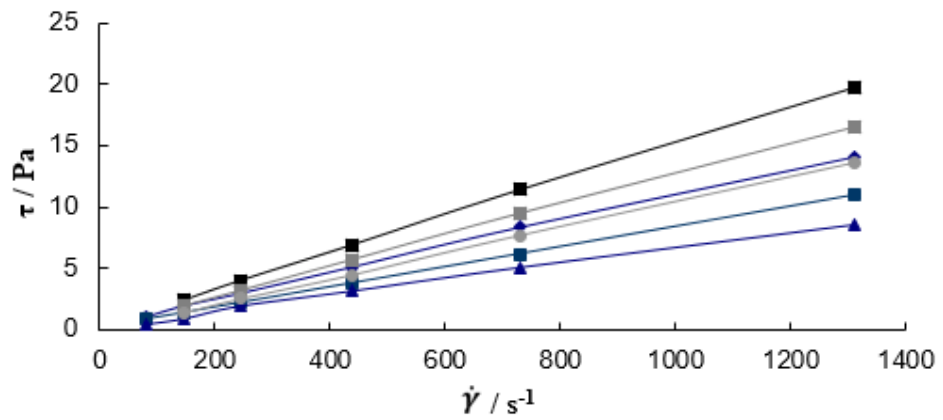

$\rightarrow \mathrm{B} 3 ; 25^{\circ} \mathrm{C} \rightarrow-\mathrm{B} 3 ; 30^{\circ} \mathrm{C} \rightarrow \mathrm{B} 3 ; 35^{\circ} \mathrm{C} \rightarrow \mathrm{A} 3 ; 25^{\circ} \mathrm{C} \rightarrow-\mathrm{A} 3 ; 30^{\circ} \mathrm{C} \longrightarrow \mathrm{A} 3 ; 35^{\circ} \mathrm{C}$

\begin{tabular}{|c|c|c|c|}
\hline Sample & Temperature, ${ }^{\circ} \mathrm{C}$ & Eq. $\tau=K \cdot \dot{\gamma}^{n}$ & $\mathrm{R}^{2^{*}}$ \\
\hline \multirow{3}{*}{$\mathrm{A3}$} & 25 & $\tau=0.0224 \cdot \dot{\gamma}^{0.944}$ & 0.99995 \\
\cline { 2 - 4 } & 30 & $\tau=0.0154 \cdot \dot{\gamma}^{0.972}$ & 0.99987 \\
\cline { 2 - 4 } & 35 & $\tau=0.01 \cdot \dot{\gamma}^{1.005}$ & 0.99965 \\
\hline \multirow{2}{*}{ B3 } & 25 & $\tau=0.011 \cdot \dot{\gamma}^{0.914}$ & 0.99985 \\
\cline { 2 - 4 } & 30 & $\tau=0.0116 \cdot \dot{\gamma}^{0.953}$ & 0.99971 \\
\cline { 2 - 4 } & 35 & $\tau=0.0105 \cdot \dot{\gamma}^{0.935}$ & 0.99736 \\
\hline
\end{tabular}

Fig. 1. Shear stress vs. shear rate for samples $A 3$ and $B 3$

Table 3

RHEOLOGICAL EQUATIONS FOR SAMPLES A3 AND B3

the correlation coefficient

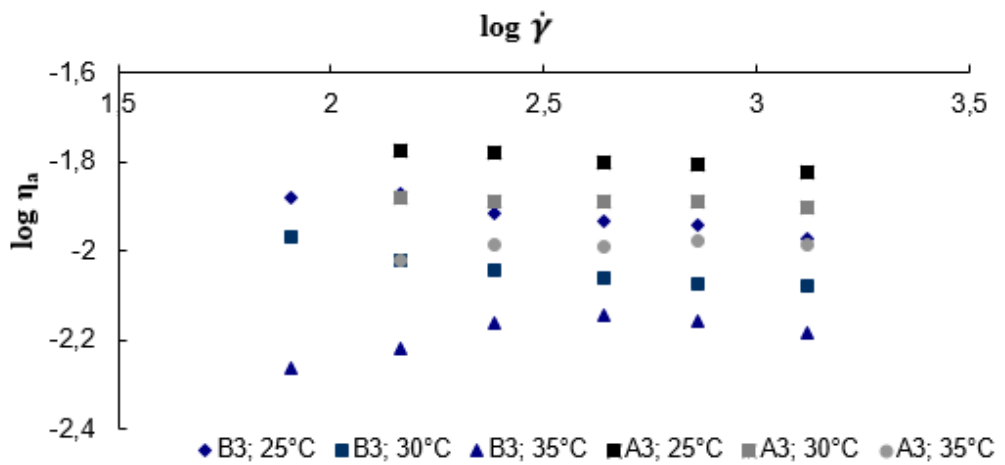

Fig. 2. Apparent viscosity vs. shear rate for samples A3 and B3 


\begin{tabular}{|c|c|c|c|c|c|c|}
\hline \multirow[t]{2}{*}{$\dot{\gamma}, \mathrm{s}^{-1}$} & \multicolumn{6}{|c|}{ Eq. $\tau=A \cdot \exp \left(E_{s} / R \cdot T\right)$} \\
\hline & \multicolumn{3}{|c|}{ A3 } & \multicolumn{3}{|c|}{ A4 } \\
\hline 145.8 & \multicolumn{3}{|c|}{$\tau=5.5 \cdot 10^{-8} \cdot \exp (5256 / T)$} & \multicolumn{3}{|c|}{$\tau=3.6 \cdot 10^{-7} \cdot \exp (4825 / T)$} \\
\hline 437.4 & \multicolumn{3}{|c|}{$\tau=9.9 \cdot 10^{-6} \cdot \exp (4012 / T)$} & \multicolumn{3}{|c|}{$\tau=1.1 \cdot 10^{-5} \cdot \exp (4116 / T)$} \\
\hline 1312 & \multicolumn{3}{|c|}{$\tau=2.2 \cdot 10^{-4} \cdot \exp (3400 / T)$} & \multicolumn{3}{|c|}{$\tau=4.1 \cdot 10^{-5} \cdot \exp (4045 / T)$} \\
\hline$\dot{\gamma}, \mathrm{s}^{-1}$ & \multicolumn{3}{|c|}{ A5 } & \multicolumn{3}{|c|}{ B3 } \\
\hline 145.8 & \multicolumn{3}{|c|}{$\tau=2.3 \cdot 10^{-5} \cdot \exp (3671 / T)$} & \multicolumn{3}{|c|}{$\tau=4.9 \cdot 10^{-11} \cdot \exp (7281 / T)$} \\
\hline 437.4 & \multicolumn{3}{|c|}{$\tau=1.8 \cdot 10^{-4} \cdot \exp (3390 / T)$} & \multicolumn{3}{|c|}{$\tau=8.5 \cdot 10^{-8} \cdot \exp (5338 / T)$} \\
\hline 1312 & \multicolumn{3}{|c|}{$\tau=4.2 \cdot 10^{-4} \cdot \exp (3455 / T)$} & \multicolumn{3}{|c|}{$\tau=3.5 \cdot 10^{-5} \cdot \exp (4534 / T)$} \\
\hline$\dot{\gamma}, s^{-1}$ & \multicolumn{3}{|c|}{ B4 } & \multicolumn{3}{|c|}{ B5 } \\
\hline 145.8 & \multicolumn{3}{|c|}{$\tau=4.1 \cdot 10^{-10} \cdot \exp (6753 / T)$} & \multicolumn{3}{|c|}{$\tau=1.15 \cdot 10^{-8} \cdot \exp (6034 / T)$} \\
\hline 437.4 & \multicolumn{3}{|c|}{$\tau=1.9 \cdot 10^{-7} \cdot \exp (5219 / T)$} & \multicolumn{3}{|c|}{$\tau=1.6 \cdot 10^{-7} \cdot \exp (5597 / T)$} \\
\hline 1312 & \multicolumn{3}{|c|}{$\tau=6.9 \cdot 10^{-6} \cdot \exp (4451 / T)$} & \multicolumn{3}{|c|}{$\tau=4.2 \cdot 10^{-7} \cdot \exp (5567 / T)$} \\
\hline \multirow{2}{*}{$\dot{\gamma}, \mathrm{s}^{-1}$} & \multicolumn{6}{|c|}{$\mathrm{E}_{2}, \mathrm{Jmol}^{-1}$} \\
\hline & A3 & A4 & A5 & B3 & B4 & B5 \\
\hline 145.8 & 43.7 & 40.1 & 30.5 & 60.5 & 56.1 & 50.1 \\
\hline 437.4 & 33.3 & 34.2 & 28.7 & 44.3 & 43.4 & 46.5 \\
\hline 1312 & 28.2 & 33.6 & 28.2 & 37.7 & 37.0 & 46.2 \\
\hline
\end{tabular}

Table 4

PARAMETERS OF ARRHENIUS EQUATION
The parameters of Arrhenius model equation which were determined from the logarithmic form of equation (2) $(\ln \tau=f(1 / T))$, for shear stress values corresponding to the three chosen values of the shear rate, are reported in table 4.

It can be seen that for all the solutions the increase of shear rate leads to the increase of the pre-exponential coefficient $A^{\prime}$ and the decrease of the activation energy. A possible explanation of the decrease in activation energy with the increase of the shear rate would be that higher velocity leads to higher turbulence and dynamic pressure, with effect on the decrease of the molecular associations and their relaxation period. Atthe same ethoxylated alcohol concentration, the samples with AGE 20 content (B3-B5) exhibit higher values for the activation energy of viscous flow.

The influence of surfactant concentration on rheological behavior was studied for the samples containing AGE 20 at $25^{\circ} \mathrm{C}$. The obtained rheological equations are show $\bar{n}$ in table 5 .

It can be noticed that regardless of the concentration, the rheological behavior is pseudoplastic, more pronounced at lower concentrations $(n<0.8)$.

The variation of apparent viscosity of these solutions is shown in figure 3 . It is noted that the apparent viscosity decreases with the increase of shear rate, more pronounced at the more dilute solutions ( $15.7 \%$ at $\mathrm{B} 1)$ and less at the most concentrated $\left(2.1 \%\right.$ at $\mathrm{B} 5$, at $\left.25^{\circ} \mathrm{C}\right)$. Also, the apparent viscosity increases with the increase of the surfactant concentration. The consistency of the solutions increases substantially at concentrations above 15\%, reaching the consistency of a gel at concentrations greater than $20 \%$.

In figure 4 is shown the influence of the degree of ethoxylation of fatty alcohols on the apparent viscosity of their solutions.
Table 5

RHEOLOGICAL EQUATIONS FOR SAMPLES B1-5 AT $25^{\circ} \mathrm{C}$

\begin{tabular}{|c|c|c|}
\hline Sample & Eq. $\tau=K \cdot \dot{\gamma}^{n}$ & $\mathrm{R}^{2}$ \\
\hline B1 & $\tau=0.038 \cdot \dot{\gamma}^{0623}$ & 0.99304 \\
\hline B2 & $\tau=0.0276 \cdot \dot{\gamma}^{0757}$ & 0.99911 \\
\hline B3 & $\tau=0.02 \cdot \dot{\gamma}^{0.913}$ & 0.99979 \\
\hline B4 & $\tau=0.0279 \cdot \dot{\gamma}^{0.926}$ & 0.99995 \\
\hline B5 & $\tau=0.058 \cdot \dot{\gamma}^{0.965}$ & 0.99997 \\
\hline & & \\
\hline
\end{tabular}

It is noted that the values of apparent viscosity are consistently higher for the solutions with AGE 50 , with a more bulky hydrophilic part (samples A) than the solutions with AGE 20 (samples B), at the same concentration (wt.\%) although the molar concentration is lower for AGE 50.

Polyethoxylated nonionic surfactants generally produce less foam and much less stable foam than ionic surfactants in aqueous media. These effects are probably due to the larger surface area per molecule and the absence of highly charged surface films in these foams [15].

The foaming power and wetting capacity of the two ethoxylated fatty alcohols were studied for aqueous solutions having concentrations ranging from $0.25 \mathrm{wt} \%$ to 4 wt.\%, higher than critical micelle concentration (CMC) $[16,17]$. 

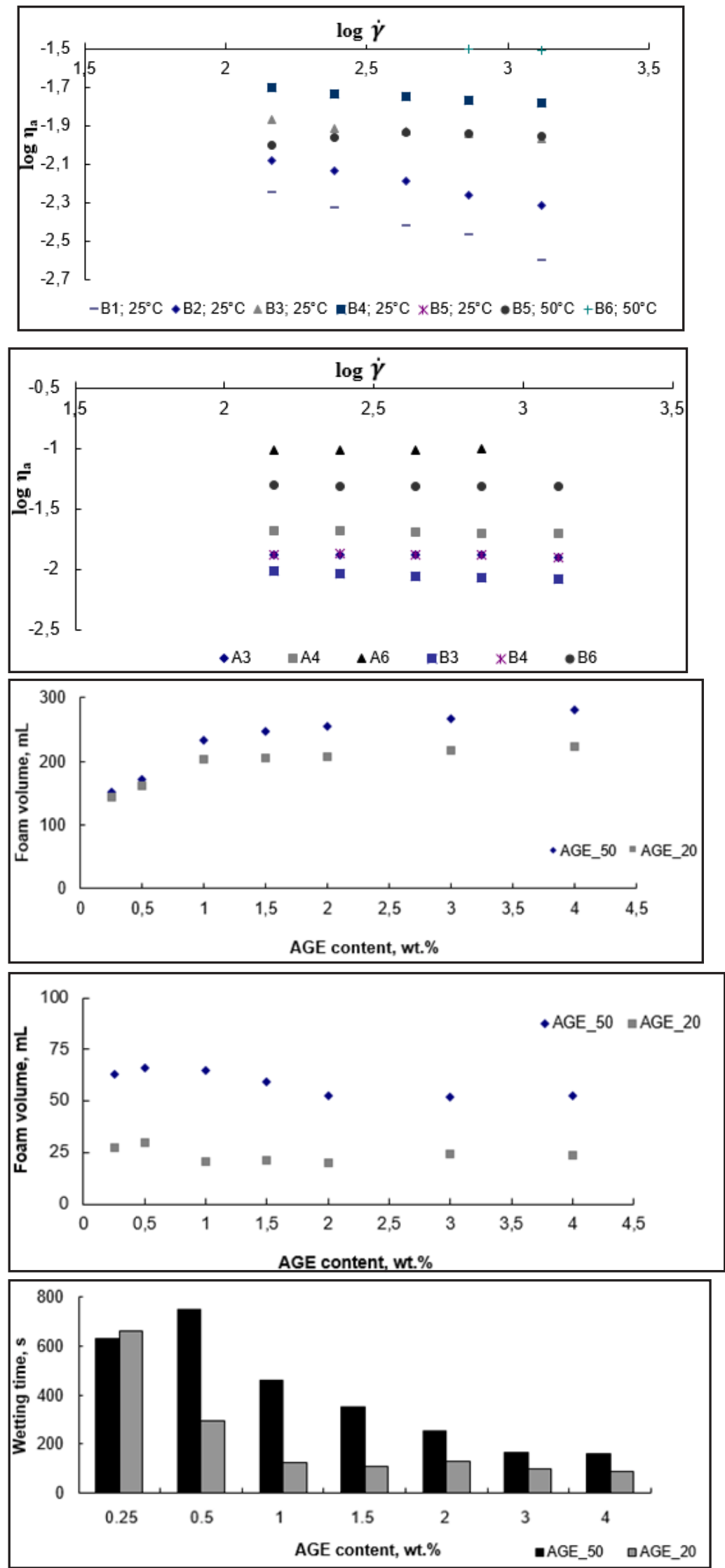

Figures $5 \mathrm{a}$ and $5 \mathrm{~b}$ show the volume of foam after $30 \mathrm{~s}$ and 5 minrespectively, depending on the figures $5 a$ and $5 b$ show the volume of foam after 30 s and 5 min respectively, depending on the surfactant concentration.

The variation of wetting capacity, expressed as average wetting time, depending on the concentration of the solution is shown in figure 6 .

This variation highlights lower wetting times for AGE 20 under similar conditions compared to AGE_50. For AGE_20,
Fig. 3. Apparent viscosity vs. shear rate for samples with AGE_20 content

Fig.4. Apparent viscosity vs. shear rate for samples $\mathrm{A} 3, \mathrm{~A} 4, \mathrm{~A} 6, \mathrm{~B} 3, \mathrm{~B} 4, \mathrm{~B} 6$ at $30^{\circ} \mathrm{C}$

Fig.5a. The foam volume vs. AGE content after $30 \mathrm{~s}$

Fig.5b. The foam volume vs. AGE content after $5 \mathrm{~min}$

Fig.6. The average wetting times vs. AGE content

more efficient than AGE 50 , the wetting capacity increases with the concentration of the solution up to $1 \mathrm{wt} . \%$, after which it remains constant on the studied concentration range, although for AGE 50 the same limitation of wetting capacity is observed starting with the concentration of 3 wt. \%.

\section{Conclusions}

The analysed samples present non-Newtonian behavior 
with flow behavior index smaller than 1, regardless of temperature, concentration of fatty alcohol and degree of ethoxylation. The decrease of apparent viscosity with increasing of shear rate is more pronounced at lower temperatures and in more dilute solutions.

For both polyethoxylated alcohols the volume of foam increases slightly with increasing concentration to $\sim 1$ wt.\%, after which it remains approximately constant across the studied range of concentration, figure $5 \mathrm{a}$.

At low concentrations, less than $0.5 \mathrm{wt} \%$, the differences in the volume of foam are insignificant, but with increasing concentrations they increase in favor of AGE 50 . These differences are even greater after 5 minutes (fig. 5b), which shows that the foam stability is higher for the surfactant with higher degree of polyethoxylation.

The results could be explained by the adoption of a helicoidal form of polyethoxylated chains in the aqueous phase which provides a greater number of cohesion forces for AGE 50 and hence a greater mechanical strength and elasticity of the film. This variation is also explained by the lower values of surface tension for the solutions with concentration $0.25 w \mathrm{wt} \%\left(\gamma_{\text {AGE_50 }}=51.25 \mathrm{mN} \mathrm{m}^{-1}, \gamma_{\text {AGE_20 }}=\right.$ $53.53 \mathrm{mN} \mathrm{m}^{-1}$ ).

\section{References}

1.FARN, R. J., Chemistry and Technology of Surfactants, Blackwell Publishing, Oxford, UK, 2006, p.136

2.ROSEN, M. . ., KUNJ APPU, J. T., Surfactants and Interfacial Phenomena, $4^{\text {th }}$ ed., J ohn Wiley \& Sons Inc., New Jersey, 2012, p. 24, 132
3.*** www.clariant.de/11.11.2013_Surfactants_Brochure_2013_final.pdf 4.*** www.clariant.de/2009_Construction_N̄ewsroom_B Brochures_ Surfactants_pdf

5.POP, M. D., RO 116645 B, 2001

6.HOLMBERG, K., JONSSON B., KRONBERG, B., LINDMAN, B., Surfactants and Polymers in aqueous solution, $2^{\text {nd }}$ ed., John Wiley $\&$ Sons Ltd, Chichester, UK, 2003, p.97

7.OBUKOWHO, P., Ingredients and Their Role in Relaxer Formulations in: Hair Relaxers Science, Design, and Application, $1^{\text {st }}$ ed., Allured Pub Corp, 2012, p.77

8.** http://ww w.tellerini.it/en/emuldac-alcs-100-sc-p361

9.*** http://interchimie.fr/data/catalog

10.RAO, M.A., Flow and Functional Models for Rheological Properties of Fluid Foods in: Rheology of Fluid, Semisolid, and Solid FoodsPrinciples and Applications, $3^{\text {rd }}$ ed., Springer Science $\&$ Business Media NY, 2014, p.28

11.TUDOSE, R. Z., Ingineria proceselor fizice din industria chimica, vol. I, Ed. Academiei Române, Bucuresti, 2000, p. 124

12.TAMAS, A., PADURE, M., VINCZE, M., Rev. Chim. (Bucharest), 67, no. 2, 2016, p.344

13.MALKIN, A.Ya., ISAYEV, A.I., Rheology: Concepts, Methods, and Applications, $2^{\text {nd }}$ ed., Chem Tec Publishing Toronto, 2012, p.131

14.KUMAR, R., MANJ UNATHA, S., KATHIRAVAN, T., VIJ AYALAKSHMI, S., NADANASABAPATHI, S., RAJU, P.S., J . Food Sci. Technol., 52, nr.9, 2015, p.5611

15.ROSEN, M. J ., Surfactants and Interfacial Phenomena, $2^{\text {nd }}$ ed., J ohn Wiley \&Sons Inc., New Jersey, 1989, p. 288, 293

16.*** SR ISO 696: 1997

17.*** SR EN 1772:2009.

Manuscript received: 12.04 .2018 